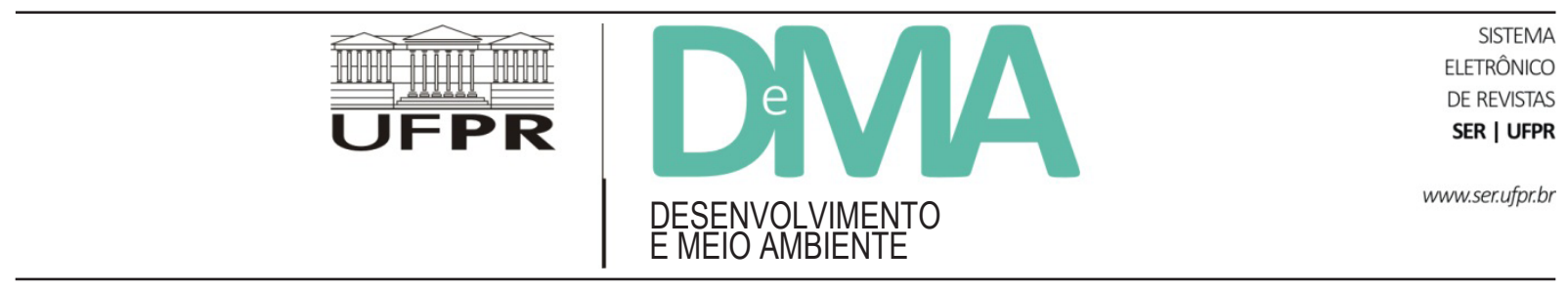

\title{
Tilheiros: carpintaria naval e sistemas territoriais em Parintins-AM
}

\section{Tilheiros: naval carpentry and territorial systems in Parintins-AM}

\author{
Estevan BARTOLI ${ }^{1 *}$ \\ ${ }^{1}$ Universidade do Estado do Amazonas (UEA), Parintins, AM, Brasil. \\ *E-mail de contato: ebartoli11@gmail.com
}

Artigo recebido em 14 de novembro de 2018, versão final aceita em 20 de maio de 2019.

RESUMO: Objetivamos analisar a atividade da carpintaria naval em Parintins, no estado do Amazonas, através de aportes teóricos pertencentes à abordagem territorial e Sistemas Territoriais. Revisitando noções que interpretam cidades enquanto sistemas-abertos, ressaltamos interações organizacionais internas da cidade (políticas, econômicas e culturais) e desta com o módulo ecológico e escalas diversas de relações com o exterior do sistema urbano e áreas de entorno da cidade. A partir da proposta analítica sobre o Sistema Territorial Urbano-Ribeirinho composto por atividades da economia popular em Parintins, averiguamos como a carpintaria naval se adapta às oscilações de sazonalidade hídrica e sítio urbano. Cadeia produtiva incompleta, ausência de reposição do estoque madeireiro e fechamento operacional do sistema territorial indicam situação frágil frente às redes de poderes locais devido à ausência de organização coletiva. Concluímos apresentando um quadro sobre o papel de apoio à economia popular e mercantil além dos aspectos culturais que interagem no ambiente urbano.

Palavras-chave: sistemas territoriais; pesca; cidade; carpintaria naval.

ABSTRACT: We aim to analyze the activity of naval carpentry in Parintins, in the state of the Amazonas, through theoretical contributions pertaining to the territorial approach and territorial systems. Assuming notions that interpret cities as open systems, we emphasize internal organizational interactions of the city (political, economic and cultural), and its interactions with the ecological module and the various scales of relations with the exterior of the urban system and surrounding areas of the city. Taking into account the analytical proposal on the Urban-Ribeirinho Territorial System composed of activities of the popular economy in Parintins, find out how naval carpentry adapts to fluctuations of water seasonality and urban site. An incomplete production chain, the absence of replenishment of the timber inventory and the operational closure of the territorial system indicate a fragile situation in comparisson with the networks of local power due to the absence of collective organization. Finally, we present a picture of the role of support to the popular and mercantile economy beyond the cultural aspects interacting in the urban environment.

Keywords: territorial systems; fishery; city; naval carpentry. 


\section{Introdução}

O sistema de análise multidimensional presente na abordagem territorial (Raffestin, 1993; Dematteis, 2005; 2008; Saquet, 2007; 2011) abrange a economia, a política, a cultura e a natureza (EPCN). Nesse sentido, evidencia lutas por sistemas de apropriação, valoração e representação, carregadas de intencionalidade dos sujeitos que disputam trunfos para o ordenamento do território. Tal método é pouco utilizado na problemática urbana, principalmente questionando o papel que cidades exercem para condicionar ações de redes de sujeitos variados.

Com aplicação de questionários semidirectivos, trabalhos de campo e realização do Primeiro Encontro de Carpintaria Naval de Parintins ${ }^{1}$, objetivamos descrever aspectos que compõe a estrutura desse subsistema urbano relativo às atividades ligadas à economia popular que estão presentes na cidade. Averiguamos ainda a capacidade de redes de sujeitos "usarem" a cidade para construção de projetos coletivos (possuindo certa identidade territorial), condicionados pelo manejo do recurso regional madeireiro.

No primeiro subitem apresentamos discussão sobre Sistemas Territoriais e cidades. Foram revisitadas teorias que interpretam cidades enquanto sistemas abertos e auto-organizativos, propensos a alterações a partir de estímulos ou perturbações externas, mas que possuem dinâmica interna cuja interação entre seus elementos garante a reprodução de seus subsistemas. Dialogamos com a proposta do modelo SLoT (Sistemas Locais Territoriais), que é instrumento analítico com preocupação operacional (Dematteis, 2005; 2008). Nele, a rede local de sujeitos, as interações com ecossistemas e as relações locais com redes globais são, entre outros aspectos, interpretados enquanto âmbito territorial para agregação de atores, possibilitando que estes construam projetos territoriais.

No segundo subitem, apresentamos a estrutura do Sistema Territorial Urbano-Ribeirinho (STUR), que contribui para o desenvolvimento de um módulo socioeconômico, organizacional e cultural pertencente à economia popular que influencia no ordenamento territorial de diversos pontos circunvizinhos à cidade. $\mathrm{O}$ ambiente urbano é interpretado como milieu, propiciando condições diversas para mediação da produção territorial.

Atravessando a estrutura do STUR (eixo mediador entre a cidade e as áreas de entorno), está a proposta central: interpretar a atividade da carpintaria naval tradicional a partir de critérios definidos para análise empírica elencados no último item do texto (considerações finais), levando em conta: a relação histórico-cultural e relações com o sítio e situação da cidade; o uso de recursos regionais e a capacidade de processamento; as características do milieu urbano; e a abrangência da área de atuação e influência econômica na dinâmica interna do STUR. Finalizamos problematizando a autonomia relativa frente a redes locais de poder e capacidade de criar relações em escalas variadas, tecendo por fim, uma reflexão geral do papel da cidade no processo de desenvolvimento territorial para proposição de circuitos potenciais.

\section{Sistemas Territoriais e cidades}

A Teoria Geral dos Sistemas (TGS), que procura derivar da definição geral de sistema enquanto complexo de componentes em interação usando

${ }^{1}$ Realizado na Universidade do Estado do Amazonas - Centro de Estudos Superiores de Parintins - dezembro de 2015. 
conceitos característicos das totalidades organizadas, admite que sistemas sociais e socioculturais escapariam de funcionalismos e concepções conservadoras, nos quais as transformações sociais adviriam da constituição de novas combinações de elementos anteriormente existentes (Bertalanffy, 2010). Nesse contexto, novas invenções surgem de acordo com o número de permutações e combinações de elementos disponíveis nas sociedades onde diversas vertentes de pesquisas sobre territorialidades humanas foram sendo desenvolvidas com centralidade no caráter coevolutivo, interpretando como o uso recursos responde por alterar e especificar as interações entre meio ambiente e socioeconomia (dimensão técnico-espacial e temporal).

Avanços já consolidados em áreas da ciência como a etnobotânica e a arqueologia na Amazônia ressaltam que a etnodiversidade existente desde o Holoceno (11 mil anos A.P.) e foi capaz de criar um acervo de plantas domesticadas (Cavalcante \& Frikel, 1973) com eficiência produtiva de alimentos e medicamentos que foram determinantes na construção de sociedades complexas. Pesquisas apontam que a floresta poderia voltar a tornar-se soberana para produção de alimentos para a manutenção de populações como foi outrora (Clement \& Junqueira, 1998). Outros prismas analíticos demonstram a dinâmica coevolutiva de sistemas ecológicos associados aos grupos autóctones por sua ampla influência na formação, composição e alteração de ambientes antes considerados "naturais". A antropóloga Berta Ribeiro (1990) já alertava para o redesenho da natureza pela intervenção da cultura.

Concomitante ao etnocídio praticado na Amazônia durante séculos de colonização, responsável por enorme perda de diversidade cultural, ocorre extinção de línguas e dialetos que davam "acesso" ao acervo de conhecimentos e interpretações sobre o meio circundante. As relações entre homem e meio foram se estabelecendo por critérios seletivos orientados pelas mercadorias que interessavam ao momento, refletindo conseguinte a inserção da Amazônia na economia-mundo. Com o aprofundamento dessa inserção, aglomerados humanos coloniais, vilas e posteriormente o desenvolvimento da rede de cidades amazônicas influíram na transformação desse processo coevolutivo causando rompimentos e reconstruções de vínculos territoriais, sendo desafio a ser encampado em pesquisas regionais.

Como reflexão ampla visando embasar projetos locais de desenvolvimento territorial, Magnaghi (2010a) desenvolve a noção de Patrimônio Territorial, que é sintetizado, pelo autor, a partir da análise de três posicionamentos: 1) dissipação/ destruição - liberação do vínculo territorial produzido pela urbanização; 2) conservação do território para geração futuras; 3) valorização, que significa produzir novos atos territorializantes que aumentem o valor do Patrimônio Territorial através da criação adicional de recursos.

A partir do viés sistêmico se desenvolvem concepções teóricas de que cidades funcionam enquanto sistemas abertos para trocas de energia (trabalho), matéria (bens) e informação (signos), sendo sujeitas a trocas com exterior enquanto totalidade formando perturbações (flutuações), comportamentos que motivam o sistema (urbano) a se reajustar pela ordem espontânea e/ou auto-organizativa (Machado, 2005). Ao mesmo tempo, estímulos externos (informação, técnicas e energia) interagem com a formação socioespacial local. Machado (1999) usa as noções de "sistemas de povoamento" como aspectos centrais das ordenações territoriais, aprofundando a partir da obra de Pumain (1995), aspectos de intencionalidades das ações relacionadas aos sistemas técnicos existentes, 
surgindo possibilidades para ocorrer processos de comunicação e criação de elos (redes engendradas pelos sistemas técnico-territoriais).

A capacidade de ajustamento dos agentes seria trivial no processo evolutivo, cujo processo de difícil mensuração é algo a ser explorado como afirma Machado, (2005, p. 29), ressaltando ainda as ações humanas tomadas como estruturas coletivas. A dinâmica da cidade como sistema em evolução depende das necessidades, percepções, estratégias e desejos dos indivíduos e dos grupos. A maior variedade de estruturas e funções amplia as redes de relações e interações, sendo os tipos de redes (mais físicas ou topológicas) objetos de estudo. Em estudo sobre redes ilegais de tráfico de drogas, Machado (2003) reflete sobre a interação dos espaços dos fluxos e os espaços dos lugares. Enfatiza um exemplo de fragilidade da economia amazônica durante o período gomífero, cujo relativo fechamento do sistema regional garantiu certa estabilidade, mas, ao mesmo tempo, alto grau de vulnerabilidade.

Nesse contexto, buscamos valorizar tais argumentos de que cidades são recursos relacionais e materiais que permitem também outros tipos de "evolução" de relações e formação de territorialidades, melhor especificadas a partir da densificação das relações territoriais das redes de sujeitos reterritorializados nas cidades. No processo acelerado de urbanização das últimas décadas na Amazônia, redes locais de sujeitos agora com vivências adensadas no ambiente urbano, adquirem e selecionam novas informações, reinterpretando antigos saberes e reconstruindo vínculos diversos com áreas do entorno das cidades. O sistema urbano passa a atingir longínquas áreas, mesmo não alterando profundamente as condições materiais das localidades perceptíveis na paisagem, na arquitetura de comunidades, ou na baixa presença de elementos técnicos como tratores, máquinas e vias de transporte e comunicação, por exemplo. Mas a economia incompleta de Parintins intensifica a necessidade de circulação fluvial ${ }^{2}$, exploração de recursos e inserção no consumo urbano de populações diversas.

Indígenas, pescadores, camponeses e ribeirinhos reinterpretam novas situações a partir da cidade: em quais fluxos (i-materiais), redes territoriais, socioambientes, relações escalares, ambientes técnicos e relações sociais estão inseridos ou podem se inserir, tendo o ambiente da cidade como auxílio na formação de novos arranjos de processamento de recursos, com possibilidade de recomposição nas relações de poder. São reelaborados sistemas territoriais mais complexos na evolução de suas relações territoriais.

A área de abrangência de tais sistemas é outro quesito chave. Implica conexões de novos pontos do território ou reforço dos antigos à cidade, retomando práticas de extração de recursos naturais regionais. Isso é incitado pela intensificação da circulação das populações através de embarcações regionais, causando maior pressão sobre espécies mais valorizadas (pesca e madeira, por exemplo) ou recursos minerais como nos garimpos de aluvião ${ }^{3}$. Surgem assim disputas pela capacidade de configurações de sistemas territoriais a partir da base de atuação urbana, pois grupos dominantes passam a influenciar o ordenamento territorial de exploração econômica.

\footnotetext{
2 A cidade não possui conexões rodoviárias em sua articulação na rede urbana regional. O sistema de transporte dominante é hidroviário. Pouca atenção tem sido dada ao sistema de transporte que a economia popular tem utilizado com uso de pequenas e médias embarcações, sendo essas, uma das principais forças articuladoras da rede urbana do baixo Amazonas (Bartoli, 2018).

${ }^{3}$ Recentemente no município de Maués, sub-região do baixo Amazonas, garimpos clandestinos se multiplicam nas cabeceiras do rio Amana, com intensificação de problemas socioambientais.
} 
Nas cidades com dinâmica ribeirinha intensa como Parintins, as complexas e multifacetadas rearticulações dessas populações passariam por novas formações de territorialidades. "Umbilicalmente" (e por questão de sobrevivência), retomam acessos a ambientes circundantes, construindo redes de interação para complementar a renda na cidade. No próximo subitem, aprofundamos essa temática demonstrando a estrutura do sistema territorial em voga (STUR).

Retomando a ideia de sistemas, a aplicação de metáforas é constante na criação de modelos analíticos para representação e análise de cidades (ONU, 1997), seja mecânica ou biológica. Camagni (2005) aponta que as características gerais necessárias de um sistema vivente (abertura, organização hierárquica em vários níveis, finalidade e diversidade) são facilmente extensíveis para o sistema da cidade. Ressalta que a única característica ainda não resolvida refere-se à finalidade, na busca da capacidade e auto-reprodução e de comportamento intencional, que estariam ausentes na cidade moderna. Isso seria aspecto importante para repensar o futuro das cidades na Amazônia: manejar o território circundante às cidades visando sua automanutenção e em proveito de suas populações.

Outra aplicação da abordagem sistêmica para entender a dinâmica urbana aparece também em Griffith \& Berdague (2006). Estes avançam na distinção entre a organização social e a biológica, ressaltando que humanos possuem a capacidade semiológica de construir relações linguísticas próprias. Tais relações permitem a comunicação social e a possibilidade de construção de uma consciência coletiva. O potencial ontogênico da cidade (explicação sobre como o sistema processa os conflitos e distúrbios) teria, no complexo-científico presente, um meio para reunir recursos e conhecimento, visando transformar a ameaça em risco gerenciá- vel. Salientam a capacidade de criar mecanismos de auto-regulação que absorvem as perturbações em busca de soluções e ciclos de reforço positivo chamados de dispositivos de revitalização urbana rumo à cidade-autopoiética.

As metáforas empreendidas pelo viés organicista insistem em considerar o grau de abertura dos sistemas urbanos. As propostas analíticas considerariam a carga "genético-evolutiva" de cada unidade, na qual a história do território é continuamente entrelaçada a impulsos e estímulos externos. Estes podem ser metabolizados como "hibridização". O estímulo externo, em certos casos, pode ser catastrófico, criando descontinuidade evolutiva (Dematteis, 2007).

Demmateis (2005), sem seguir derivação determinista e criticando analogias forçadas com a biologia, levanta possibilidades para análise de sistemas territoriais numa ótica evolucionista. Segundo o autor, a coevolução sociedade-ambiente em seu mecanismo reprodutivo tem como condição de estabilidade nas relações econômicas com certo espaço geográfico (e por isso ecológico). Essa relação alimenta um processo coevolutivo que contém o principal agente formador da diversidade cultural (Demmateis, 2005, p. 73). Faz também levantamento de características internas na evolução de Sistemas Locais Territoriais (SLoT) em sua complexidade, que resumidamente: são organizados por módulo que envolvem matéria, energia e informação; são sistemas cognitivos e auto-reguláveis; dependem de conexões internas e externas, onde fragmentações colocam em risco os sistemas territoriais; coligam componentes internos funcionalmente capazes de fazer a automanutenção do sistema; são vulneráveis; possuem plasticidade e um certo grau de desordem e, portanto, muito complexos.

O modelo SLoT é útil para averiguação dos mecanismos de evolução interna de sistemas indi- 
vidualizados e hibridizados. Abertos a trocas com o exterior, pretende, a partir da abordagem territorial, analisar um determinado nível na hierarquia genético-cultural numa ótica evolucionista. Ou seja, "uma unidade de base na transmissão de informação necessária para conservar e replicar no tempo certo pacote de informação, equivalente cultural de um genoma de uma espécie" (Dematteis, 2005, p. 104).

Para o autor, a diversidade no interior do sistema é entendida como variabilidade potencial. Isso aumenta a gama de escolhas possíveis, sendo recurso estratégico na escala evolutiva do sistema. Ele também considera essa diversificação (cultural, social, institucional e produtiva) como resultado de processos coevolutivos de longa duração das sociedades locais com o território e o ambiente. Essa "riqueza coletiva desenvolve papel de pool genético-cultural, cuja transmissão acresce a capacidade inovadora e a autonomia dos sistemas territoriais nas diversas escalas (Dematteis, 2008, p. 43)".

Como modelo científico, o SLoT propõe descrever a relação entre interação social, potencialidades do território local, governança e desenvolvimento. Através da rede local de sujeitos e suas relações com a especificidade territorial (milieu), busca interpretar ações, onde o território se comporta em certas circunstâncias como sujeito coletivo (Dematteis, 1995). Objetivamos levantar contribuições e limitações do modelo SLoT que serve como fonte de ricas ideias e reflexões teórico-conceituais. Apesar do contexto empírico italiano do chamado grupo de Turim $^{4}$ ser bastante diferenciado da realidade Amazônica e Latino Americana, as contribuições são enormes na análise territorial.

As propostas de desenvolvimento local, como as de Dematteis $(2005 ; 2007 ; 2008)$ e Magnaghi (2010a; 2010b) são embasadas na valorização do território local, que seria resultado da longa interação de relações sociais atreladas ao sedimento territorial. Neste, a cultura, as representações simbólicas e a relação com o milieu devem ser (re) valorizadas em projetos alternativos que, mesmo possuindo viés utópico, partem da reapropriação do saber contextual e comunitário na busca da consciência do lugar (Magnaghi, 2010b, p. 57) por parte dos sujeitos e suas redes de cooperação locais. Evitar a nostalgia, "museificação" e práticas pseudo-conservativas torna-se necessário desde que se tenha a configuração do território entendida através da interpretação das relações tecidas pelos sujeitos. Dentro do contexto urbano, estas formam sistemas que conservam memória histórica e de práticas produtivas, entre outras.

O específico meio material e cultural do local, como carga "genético-evolutiva" das relações de longa duração, é central como recurso. Entretanto, ao analisar a possível busca de autonomia de determinados grupos, devemos evitar o erro em pesquisas de não considerar suficientemente o entrecruzamento que se estabelece entre território, práticas sociais dominantes e as subalternas como consideram Sommella \& Viganoti (2005). Deve-se evitar também cair em mitos e simplificações localistas, que minimizam os conflitos políticos e econômicos locais, as estruturas de dependência inter-regionais, ou desconsideram tensões advindas da estrutura de classes sociais e do ambiente macroeconômico. Obviamente, como modelo, o SLoT possui debilidade em análise de territórios cujas relações de pobreza ocorrem mediante perpetuações de elites atreladas ao capital mercantil, baixos índices de alfabetização e qualidade do ensino, fraca coesão de setores

\footnotetext{
${ }^{4}$ Grupo de Turim - Itália, coordenado por Giuseppe Dematteis na Universidade de Turim, envolve vários pesquisadores importantes como Sérgio Conti, Ana Segre, Francesca Governa, Egídio Dansero, Carlo Salone, oriundos do Politécnico e Universidade de Turim e outras universidades, como Vincenzo Guarrasi, Bruno Vecchio e Paola Bonora.
} 
populares com fortes relações de dependência a políticos locais e insuficiente engajamento popular nas discussões e ações políticas locais.

Dematteis (2008) apresenta um guia metodológico para construção do modelo SLoT com centralidade no conceito de territorialidade ativa, valorizando as ações coletivas territorializadas e territorializantes dos sujeitos locais e objetivando construção de estratégias de inclusão. A construção do modelo partiu de pesquisas empíricas sobre políticas públicas na Itália ${ }^{5}$. O intuito foi analítico e visou a construção de uma base teórica que auxilie o planejamento territorial, resumidamente composto pelos seguintes elementos (Dematteis, 2008, p. 3637): i) rede local de sujeitos presentes ou ativáveis, que agem de algum modo como ator coletivo; ii) o milieu local como conjunto de condições favoráveis do contexto territorial que o opera a rede de sujeitos; iii) a relação de interação da rede local com o milieu e com os ecossistemas locais; iv) a relação interativa da rede local com redes globais. Esses elementos indicam auto-organização do sistema local considerada como recurso endógeno (verdadeiro objeto de análise para cada sistema territorial) a ser conhecido pelas políticas gerais de desenvolvimento.

Um agregado de sujeitos se comportando como sistema territorial coligando a individualização e delimitação do âmbito territorial no qual agem é o que daria a delimitação do sistema local territorial. Pré-condições subjetivas e objetivas são confrontadas, devendo-se considerar também as áreas de contenção dos fluxos locais. A síntese do modelo é apresentada na Figura 1.

Bagliani \& Dansero (2005) propõem uma releitura do SLoT através do reforço da bimodularidade do sistema acima representado. Nesta, o módulo social (componente socioeconômico) interage com o módulo natural (componente socioam-

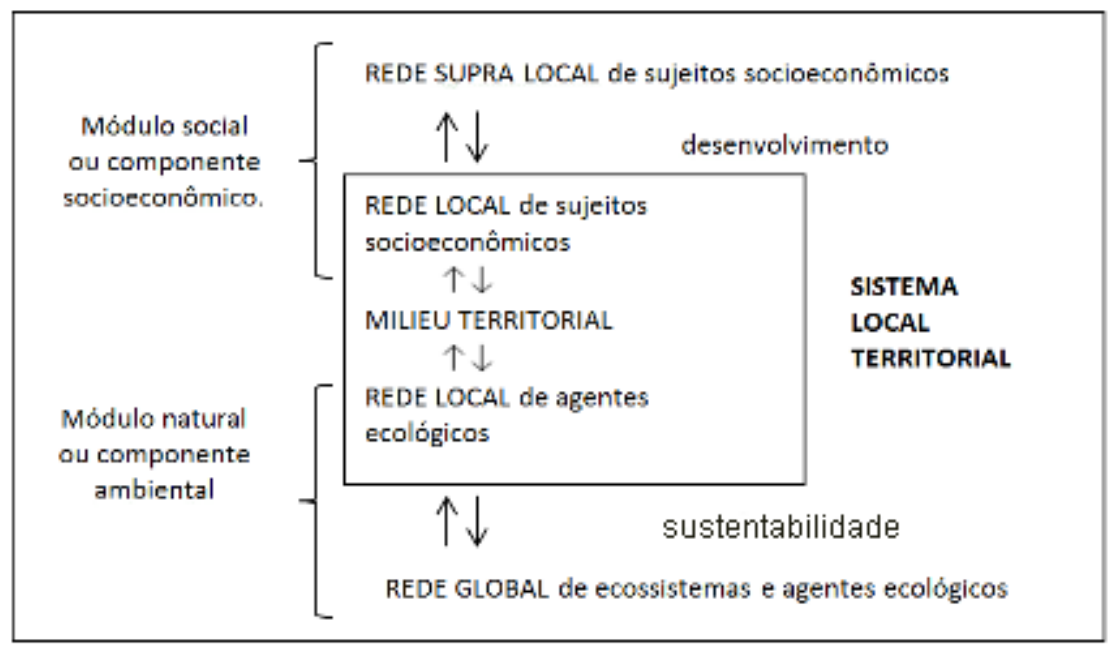

FIGURA 1 - A rede local de agentes ecológicos e a rede global de ecossistemas no interior da descrição do SLoT.

FONTE: adaptado de Bagliani \& Dansero (2005).

${ }^{5}$ PRIN: Progetti di Rilevanti Interessi Nazionali; MIUR: Ministero dell'Istruzione, dell'Università e della Ricerca. 
biental) através da mediação exercida pelo milieu. Nesse contexto, é fundamental o reconhecimento de trocas de bens de cada importação e exportação dentro do sistema com seu exterior. Ressaltam que é importante refletir sobre os limites mais apropriados para delimitar regiões e construir balanços ambientais sustentáveis. A partir do enfoque ecossistêmico, questionam que o SLoT não coincide necessariamente com qualquer fragmentação político-administrativa ou funcional, uma vez que seu âmbito territorial tem base na agregação dos atores a suas ações territoralizadas.

Muito difundida na literatura que valoriza os lugares-rede, a noção de milieu é basilar entre os autores propositores do modelo SloT. Para Dematteis, o milieu significa um conjunto permanente de características socioculturais sedimentadas em certa área geográfica através da evolução histórica de relações intersubjetivas a sua volta com as relações e modalidades de utilização dos ecossistemas naturais locais (Dematteis, 1995, p. 101). A autora complementa tal concepção (Dematteis, 2008, p. 36) adicionando o contexto territorial, no qual opera certa rede local de sujeitos. Salienta também o conjunto de condições territoriais favoráveis ao desenvolvimento e a forma como os sujeitos percebem essas condições. Enfatiza, ainda, a interação entre recursos materiais e imateriais sedimentados localmente como processo longo de coevolução.

A sobreposição das dimensões naturais e físicas (zonais) às sociais e relacionais (culturais, político e econômica) que o território possui, demonstra, na leitura dos autores propositores do SLoT, uma visão renovada de território útil para análise de dinâmicas ativadas a partir do milieu.

Quais contribuições os autores do modelo SLoT nos trazem contribuindo para a construção do modelo STUR? Alertam e supervalorizam a análise interativa entre o meio ambiente local e a maneira com que as redes de sujeitos o interpretam enquanto recursos utilizáveis, mas ressaltando a capacidade organizacional de tais redes. Essa interação (módulo organizacional/módulo ambiental) fustiga mensuração e caracterização do milieu local, que sinaliza se tal sistema territorial possui capacidade de autorreprodução não predatória, nos inspirando a averiguar práticas de sujeitos da economia popular. Informações, condições de contexto e evolução da posição dos grupos estudados em Bartoli (2017) foram apreendidos e facilitados pela maneira como se interpreta o território e seus recursos (também relacionais por sinal). Através do viés sistêmico, temos noção do grau de abertura a relações externas, mas, principalmente, de como a cidade torna complexa a evolução das relações territoriais. A quantidade de conexões, trocas de experiências, adaptações técnicas e projeção das ações se tornam mais densas junto ao milieu urbano parintinense.

Uma crítica sobre esse tipo de abordagem sistêmica ocorre devido à existência de relações hierárquicas inter-regionais e à submissão de setores populares às redes de poder locais que limitariam potenciais das localidades. Isso diminui a capacidade de reação ou escolhas do local frente às fortes pressões advindas do exterior. O resultado é a limitação da capacidade dos locais em construir saídas autônomas, como salienta Brandão (2007), mas possuindo riquíssimas possibilidades para análise de sistemas territoriais, como é o caso do Sistema Territorial Urbano-Ribeirinho.

\section{A proposta metodológica do Sistema Territorial Urbano-Ribeirinho}

As interpretações acadêmicas sobre cidades na Amazônia encampam aspectos sobre a maneira que estas interferem na produção do espaço regio- 
nal. entre outros, Características das cidades (em sentido geral) levam em conta sua centralidade e polarização: destaque aos papéis de mediação, influência política e cultural ou em sua responsabilidade territorial (Schor \& Oliveira, 2016, p. 39) ${ }^{6}$. Isso ocorre seja num papel logístico conectando modais diversos de transporte, seja funcionando como centros de fornecimento de serviços e distribuição e mercadorias para áreas de entorno (incluindo Terras Indígenas e Unidades de Conservação). Cidades na Amazônia possuem milhões de consumidores e abrigam sedes de instituições públicas e privadas, facilitando acesso a serviços de saúde, ensino, entre outros.

Pressupostos teóricos que indagam a capacidade de cidades na Amazônia de ordenar territórios de entorno apontam que a maioria das economias urbanas não possui hinterlândias consolidadas (Becker, 2013, p. 21), apresentando economias pouco diversificadas e de baixo dinamismo. Porém, frente ao acelerado processo de crescimento urbano e êxodo rural, populações diversas tem reconstruído práticas espaciais associadas a novos elementos condicionantes a partir da cidade, o que nos leva a entender que outras dinâmicas e diversificações estão presentes em cidades como Parintins. Com a intensificação da circulação sub-regional (navegação fluvial), ocorre retomada ou manutenção de vínculos territoriais com áreas do entorno, e intensificação no uso de recursos naturais pela economia popular.

Para análise desse comportamento espacial, apresentamos em Bartoli (2017) proposta metodológica relativa à existência de um sistema territorial que funciona como articulador de pontos variados no território sob influência da cidade, partindo de ações de redes de sujeitos ligados a atividades da economia popular de extração e processamento de recursos regionais e distribuição de produtos industrializados. Os subsistemas que compõem o STUR são delimitados por tipos de atividades organizadas por coletivos organizados. Combinam dinâmicas diversas que interagem com o sistema mercantil dominante (Sistema Territorial Urbano-Fluvial STUF), realizando mediação entre a cidade e o Sistema Territorial Ribeirinho.

Resumidamente, o papel mediador que o STUR possui aparece em cinco vertentes: i) zonal e topológico, conectando a cidade através de redes temáticas a pontos diversos do entorno sub-regional pela navegação, possuindo forte influência de oscilações sazonais hídricas; ii) produção e configuração de fragmentos do espaço intraurbano, constituindo fixos úteis para a navegação, por exemplo, condicionados por aspectos físicos do sítio e situação da cidade; iii) dinâmica econômica dual e complementar, sendo ativada principalmente pela economia popular (redes de sujeitos distribuem produtos industrializados e extraem/processam recursos regionais) em interação constante com as esferas de valorização do capital mercantil dominantes na cidade (em alguns casos, saltos escalares ocorrem em relações diversas que ultrapassam a sub-região); iv) organizacional e institucional, outros tipos de coalizão de sujeitos ganham relevância (cooperativas, associações, colônias de pescadores, etc.), mediando ações que se desdobram em práticas sobre o território; v) simbólico-cultural como traços da cultura cabocla e ribeirinha, indígena ou de conhecimentos populares que são absorvidos e ressignificados pela inserção ao processo urbano.

\footnotetext{
${ }^{6}$ Schor \& Oliveira (2016) enfatizam a presença de serviços de saúde em Parintins, o que aumenta sua responsabilidade territorial, pois a cidade passa a atender municípios circunvizinhos.
} 
O STUR é extremamente necessário para as atividades realizadas no sistema territorial mercantil dominante, sendo impulsionado e explorado este. É possível afirmar, portanto, que há formação de um Sistema Territorial Urbano-Fluvial (STUF) atrelado a esse capital mercantil ${ }^{7}$, que cada vez mais se sobrepõe e absorve dinâmicas ribeirinhas. Isso é perceptível pela apreensão da paisagem e mapeamento de usos do solo urbano beira-rio associado aos relatos dos pescadores (exercícios de cartografia participativa - Bartoli, 2017). Usamos o termo fluvial considerando que, para os sujeitos que impulsionam esse sistema, os rios são usados primordialmente para circulação de mercadorias. Não há intenção de manter práticas diárias, que tem no rio um aspecto simbólico, cultural/identitário (ribeirinho), lúdico ou de subsistência, sendo um sistema vinculado a atividades ligadas a relações escalares diversas, principalmente com a metrópole Manaus.

De maneira resumida, a Figura 2 apresenta a interação e composição entre os sistemas. As circunferências pontilhadas (permeabilidades e interpenetrações) representam abrangência dos sistemas e interações entre STUR e o STUF, atingindo

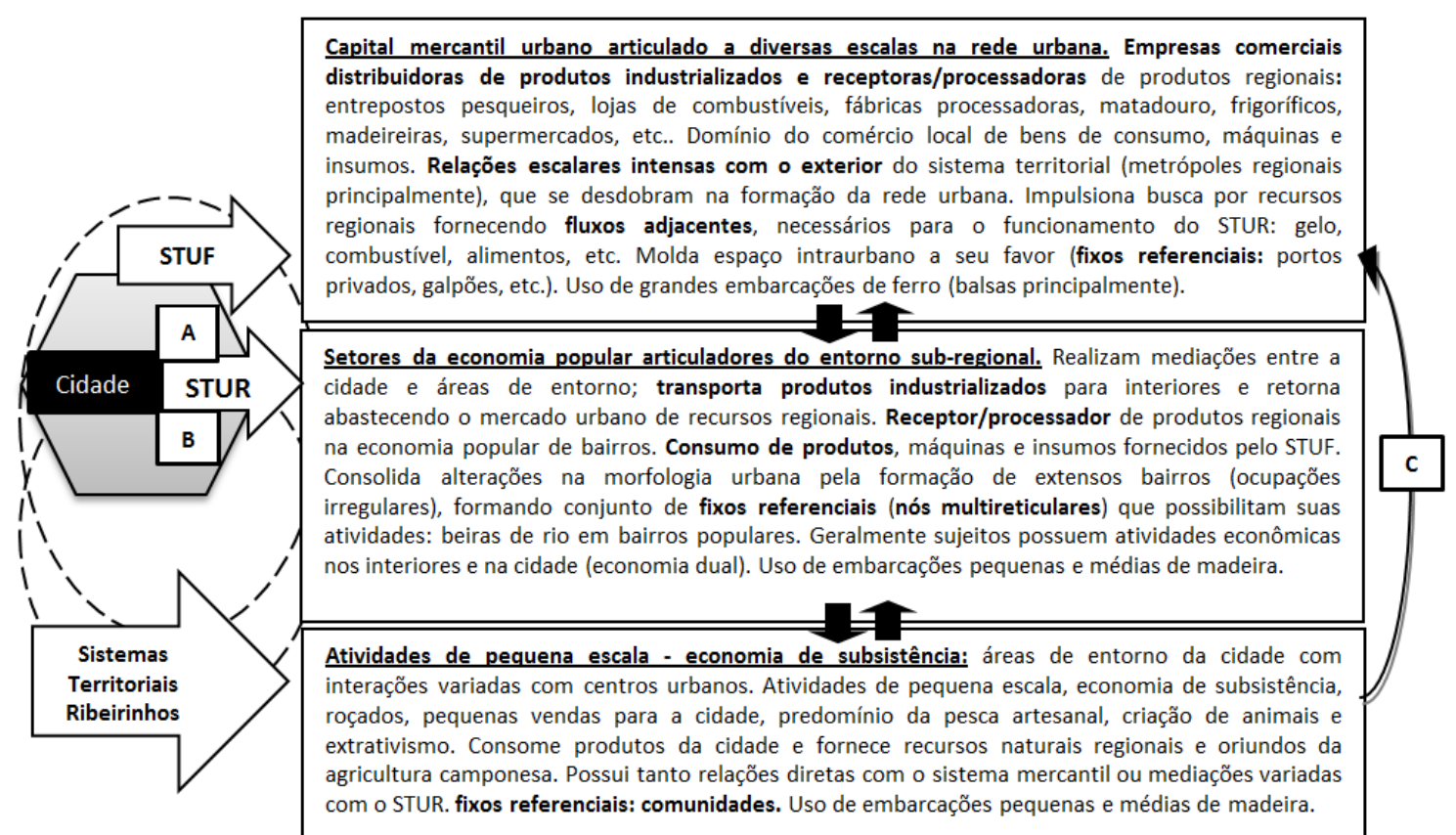

Legenda: A - Tensões e conflitos: produção do espaço urbano (ênfase nas beiras de rio). B - Hibridização: elaboração de soluções criativas e adaptações técnicas em instrumentos de trabalho, moradia, tipos de embarcações e outras formas espaciais perceptíveis em bairros populares. C - Extração de recursos regionais (inclusive areia e seixo para construção civil) realizada por empresas comerciais da cidade; ausência de mediações ou processamento na cidade, mantendo sujeitos populares que abastecem tal fluxo em grau elevado de territorialidade passiva.

FIGURA 2 - Fluxograma resumo das interações entre sistemas territoriais mediadores da influência urbana. FONTE: Organizado pelo autor.

\footnotetext{
${ }^{7}$ Há variada pulverização dos investimentos do chamado capital mercantil, que em constante metamorfose se adapta a diversas circunstâncias e cenários. No caso de Parintins, tais esferas também se aproveitam do boom gerado pelo sucesso do Festival Folclórico, se inserindo em atividades hoteleiras, redes de supermercados, agências de turismo, empresas de locação de equipamentos de som e iluminação, etc.
} 
sistemas territoriais ribeirinhos de baixa interação com a cidade.

A noção do STUR enquanto sistema que media atividades diversas da cidade em interação com áreas de entorno tem na carpintaria naval base para as constantes adaptações devidas à intensidade de trocas por transporte fluvial, complementando assim o Sistema Territorial Urbano-Fluvial (STUF), pois consomem peças, motores, combustível e tantos outros itens fabricados pelo circuito superior (grandes empresas fabricantes), adaptando-os aos barcos locais. Tais itens são vendidos pelas empresas comerciais da cidade, compondo parte importante da economia urbana.

Também constroem e adaptam barcos tradicionais para novos usos mais ligados ao setor fluvial-mercantil (barcos postos de combustíveis, empurradores, etc.). Vem ocorrendo uma adaptação constante do Sistema Territorial Urbano-Ribeirinho às práticas mercantis que acompanham fluxos e refletem a divisão territorial do trabalho. As embarcações passam a cumprir funções diversas ao comando das atividades urbanas. Outro indicador é a presença das lojas fornecendo motores novos e bancos com financiamento com o qual proprietários de embarcações conseguem modernizar as máquinas de acordo com suas necessidades.

As embarcações seguem sendo transformadas de acordo com alterações na divisão territorial do trabalho e com a influência da cidade em processar maior quantidade de matéria-prima. Batelões, cascos médios de embarcação regional (de 12 a 14 metros), passaram a ser adaptados para se tornarem empurradores, demandando pisos superiores que recebem a cabine de comando devido à extensão da balsa. A fabricação exige resistência às turbulências de grandes caudais hídricos, podendo receber alterações e usos diversos conforme a necessidade do momento. Essa flexibilidade que o batelão comporta não é apenas um meio de transporte, mas mediadora territorial que internaliza múltiplas dimensões.

O batelão faz parte da cultura regional de adaptação do homem ao meio cada vez mais urbanizado. As obras e adaptações são feitas dependendo do uso e da dinâmica do sistema a que pertencem e da estratégia territorial (territorialidade) que seu proprietário desenvolve. O batelão de madeira é, assim, constantemente adaptado, sendo conector multifuncional que internaliza contradições do tipo de sistema territorial a que está vinculado. Espaço de vida e construtor de fluxos, também se torna "lugar" de reprodução da vida devido a seu lento navegar, impelindo parte das relações familiares no interior da embarcação. O tempo do relógio nem sempre é o que comanda, prevalecendo outras temporalidades e ritmos da natureza.

Como o aprofundamento da globalização do capital tende cada vez mais a destruir formas de produção artesanais, impondo certa unicidade das técnicas (Santos; Silveira, 2003), a carpintaria naval parece resistir a tais desígnios uma vez que atua na permanência e continuidade do saber regional. Embora paulatinamente sujeita à economia urbana, essa resistência denota papel central na configuração do STUR: o de fornecer possibilidades de "retorno ao território" aos moradores da cidade, assim como acesso a moradores de interiores à cidade.

Contemplando a estratégia interativa de metodologia de pesquisa, organizamos em 2015 o Primeiro Encontro de Carpintaria Naval de Parintins. O objetivo foi dar maior visibilidade e auxiliar a retomada da antiga associação que fora abandonada. $\mathrm{O}$ debate visou discutir os rumos da atividade, dificuldades, anseios e a possibilidade de formação da cooperativa de carpinteiros navais. Ao longo do debate, construímos com auxílio dos participantes um quadro síntese sobre as forças (fortalezas) e fraquezas do setor (Tabela 1). Somados às consta- 
TABELA 1 - Quadro síntese final dos resultados do $1^{\circ}$ Encontro de Carpintaria Naval.

\section{Fortalezas}

- tradição de construção na cidade;

- existência de verba para setor;

- mercado vasto a ser explorado;

- matéria prima ainda acessível na região;

- aumento do número de encomendas;

- vendas para suprir demandas de agricultores através do

PRONAF.
Fraquezas

- baixo nível de escolaridade dos trabalhadores e pouca busca por qualificação;

- mão de obra experiente escassa;

- desvalorização da profissão;

- falta da capacitação local;

- ausência de legalização de madeira e/ou manejo

deficiente;

- áreas reduzidas para trabalho em beiras de rio;

- não há contribuição previdenciária;

- custos crescentes;

- reaproveitamento de madeira inexistente;

- impacto das cheias e vazantes pelo custoso deslocamento.

FONTE: Dados coletados e sistematizados participativamente no $1^{\circ}$ Encontro de Carpintaria Naval de Parintins. Organizado pelo autor.

tações de trabalhos de campo, os carpinteiros navais nos auxiliaram na caracterização desse subsistema apresentada a seguir.

Os relatos de componentes da antiga associação revelaram a fragilidade desta quando não conseguiram concessão de verbas em diversas ocasiões. Há uma série de oportunidades nesse sentido. Programas federais para acesso a crédito, concorrência de editais para construção de embarcações para o sistema de saúde e transporte escolar, capacitação, entre outros. Todavia, essas só podem ser acessadas através de cooperativa, o que propiciaria maior densidade de relações com o meio externo a partir do coletivo organizado.

Como resultado do encontro, foram encaminhadas medidas para o início da organização da cooperativa. Delegaram-se aos filhos dos carpinteiros e estudantes com maior habilidade para questões técnico-burocráticas responsabilidades para tal tarefa. É um avanço importante almejando futura troca de conhecimentos e aprendizado coletivo, fortalecendo a coesão do grupo.

\section{O Subsistema Territorial dos Estaleiros Navais de Parintins}

O aprendizado da profissão de carpinteiro naval, conhecimento tácito e cultural repassado entre gerações por hábeis mestres detentores de conhecimento ágrafo, depende do ambiente de relações familiares ou das relações informais nos estaleiros navais. Nesse contexto, ocorre a socialização de saberes como etapa da aprendizagem de forma lenta, pois é baseada na observação e praticada com técnicas rudimentares, mesclando evolução de ferramentas manuais e máquinas elétricas modernas.

A escassez de trabalhadores no ramo foi queixa unânime entre os carpinteiros mais experientes entrevistados. $\mathrm{O}$ repasse do conhecimento depende da existência de uma estrutura hierárquica entre mestres, artesãos e aprendizes, cada vez mais rara na estrutura de trabalho interna dos Tilheiros. Vários fatores influenciaram tal situação, como a pressão de leis trabalhistas que cerceiam e proíbem 
a presença de crianças no ambiente de trabalho. A falta de interesse dos mais jovens no aprendizado da carpintaria e a constante migração de carpinteiros mais experientes para outras atividades (moveleira principalmente) também são fatores que dificultam contato mais duradouro com possíveis aprendizes.

Geralmente, os mestres são proprietários de pequenos estaleiros, tendo herdado dos pais e avós a incumbência de continuar as atividades. Acompanham as etapas produtivas de acordo com o grau de dificuldade e confiança no carpinteiro que executa a tarefa e estão mais presentes auxiliando os mais jovens para que não ocorra perda de material ou atraso nos afazeres. Pela cultura da conversa e da observação, a circulação de saberes se transforma em "situações de aprendizagem" (Brandão, 2007) relacionadas ao tipo de convívio que cada grupo constrói.

Não houve relatos quanto ao grau de abertura do sistema referente a trocas de informações, contatos e vínculos institucionais. Isso denota certa invisibilidade da atividade junto aos órgãos locais e iniciativas de valorização. No SENAI local não há nenhum curso técnico voltado à atividade. A associação existente não conseguiu ganhar adesão e evoluir para estágio organizacional de cooperativa. Por esse motivo, a interação entre os mestres proprietários de estaleiros navais ou entre os trabalhadores informais é baixa, como constatado no encontro supracitado.

Entrevistamos os carpinteiros navais mais antigos de Parintins, hoje proprietários de estaleiros, que nos relataram que o ciclo econômico local da cultura da juta (1960-1980) atraiu para a cidade mestres carpinteiros de diversas cidades vizinhas como Santarém, Terra Santa e Oriximiná (ambos do estado do Pará). Assim como nos sistemas de movelaria ou do guaraná (Bartoli, 2015), informação e aprendizados passam a se replicar dentro do sistema urbano e adquirem novas características, se transmutando e se adaptando conforme as necessidades e demandas locais.

Esses carpinteiros descreveram espécies de madeira hoje não mais usadas na carpintaria naval de Parintins como loro, cedro e o itaubão (mogno). A escassez causada pela exploração e a pressão dessas valorizadas espécies acarretou o encarecimento do metro cúbico comprado atualmente. Os vendedores adicionam os custos das distâncias cada vez maiores percorridas para a retirada da madeira e das dificuldades de transporte. Os locais de extração estão cada vez mais distantes das margens de rios em altos cursos, exigindo maior deslocamento em estradas de terra rudimentares. As distâncias longínquas de retirada da madeira são estratégias para dificultar a fiscalização do IBAMA.

Segundo o projeto Transporte Hidroviário e Construção Naval na Amazônia (THECNA) ${ }^{8}$, dois problemas afetam os estaleiros com uso predominante de madeira. O primeiro consiste no difícil acesso à verba oferecida pelas instituições de financiamento, pois o dinheiro é direcionado a estaleiros que trabalham com aço, alumínio e ferro. O segundo está relacionado a conflitos com órgãos de proteção ambiental como o IBAMA (Instituto Brasileiro do Meio Ambiente e dos Recursos Renováveis) e o IPAAM (Instituto de Proteção Ambiental do Amazonas). Estes alegam ausência de plano de manejo florestal por parte dos Estaleiros ou fornecedores, o que contribui para a crescente escassez de madeiras nobres da região, tais como a Itauba, o Cumaru e a Sucupira-amarela.

Quando questionamos a tipologia atual das embarcações, entrevistas afirmaram haver décadas

${ }^{8}$ THECNA - Transporte Hidroviário e Construção Naval - Relatório sobre Construção Naval. Manaus, 2008. http://www.thecna.ufam.edu.br 
desde que barcos com mais de 25 metros foram constuidos em Parintins. Estes estão sendo substituídos paulatinamente pelas embarcações de ferro devido à maior segurança ${ }^{9}$. Normas recentemente criadas visam impedir que passageiros sejam transportados em barcos de madeira para Manaus. Mas os famosos e muito fabricados batelões continuam sendo os preferidos por pescadores e populações interioranas devido a espaço maior, conforto, estabilidade e capacidade de carga e, principalmente, o preço. Outro aspecto muito citado foi a presença de balsas cada vez mais numerosas na cidade, forçando a conversão de barcos regionais em empurradores.

Dos estaleiros visitados, constatamos estrutura de funções de trabalho variáveis, mas com poucos trabalhadores fixos. Estes migram entre as unidades de acordo com a disponibilidade de trabalho.

O sítio, a situação e as sazonalidades dos ritmos da natureza afetam os ritmos de trabalho. Normalmente, em setembro, a lagoa da Francesa que possui oito estaleiros costuma apresentar rápida vazante. Entretanto, em 2015 as águas ainda propiciaram navegação pela anormal lentidão na sua descida, que acelerou somente a partir do décimo quinto dia. Assim, as atividades nos tilheiros puderam estender as vantagens do acesso à lagoa por mais alguns dias. Rapidamente terminados, os batelões são lançados na água e encaminhados para outro estaleiro. Ali será realizada a chamada obra morta (obras acima do piso: cabine de comando, casa de máquina, tolda, etc).

Com o espelho d'água muito baixo,fundo e lamacento a poucos palmos da superfície, acompanhamos a descida de um batelão de 14 metros no tilheiro do Eraldo. Lentamente o barco foi sendo deslizado em caibros untados com óleo queimado, técnica empregada para que não haja abrupta entrada na lagoa e possível encalhamento do barco (figura 3). As práticas espaciais dessa atividade semi-artesanal estão ligadas aos ritmos das águas. Pelas oscilações de secas e vazantes dos últimos anos, as mudanças dos níveis fluviais têm exigido grandes esforços de adaptação dos grupos para realização da fabricação de embarcações.

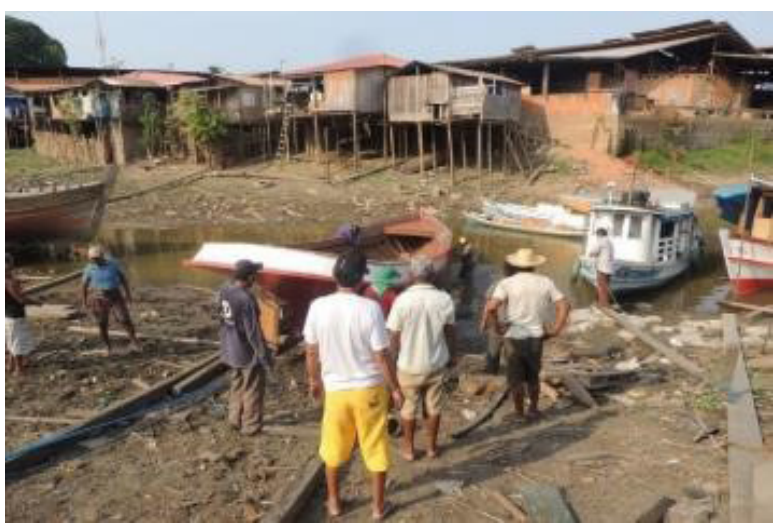

FIGURA 3 - Descida de batelão para a lagoa da Francesa durante a vazante no Estaleiro do Eraldo.

FOTO: Estevan Bartoli (08/10/2015).

De acordo com relatos, em anos de vazantes rápidas e intensas, muitos mestres deslocam suas equipes no canal da lagoa que a liga ao rio Amazonas, margeando o matadouro municipal e exigindo grande esforço de deslocamento. Para esses trabalhadores, o rio realmente parece condicionar a vida.

Constata-se a existência de centralidades sazonais e fragmentos importantes no espaço intraurbano como conectores da cidade a diversos pontos no território, zonas de contato e permeabilidade entre

\footnotetext{
${ }^{9}$ Como exemplo, em julho de 2016 o navio de madeira Coronel Tavares colidiu com tronco de madeira, o que causou seu naufrágio. Não houve vítimas, pois o comandante encostou rapidamente na margem. Atualmente, os carros de som publicitários que circulam em Parintins oferecendo passagens para "a capital da Zona Franca", frase utilizada pelo anunciante, ressaltam sempre como atrativo e diferencial se as embarcações são de ferro.
} 
os ambientes "urbano e o ribeirinho". As novas formas-conteúdos em beiras de rio nos bairros, as ocupações irregulares, os antigos bairros de pescadores ou os portos privatizados por empresas comerciais da cidade denotam diferentes temporalidades, lógicas de uso e apropriações do espaço. Indicam, até mesmo, conflitos e disputas visando uso exclusivo dessas beiras de rio. Nos últimos dez anos, pela pressão de agentes pertencente ao STUF, três tilheiros foram substituídos por portos particulares.

Parintins se firma, assim, como polo sub-regional da atividade de fabricação de barcos de madeira devido aos seguintes fatores: disponibilidade de mão-de-obra com longa experiência e baixo custo; condição de centro comercial de distribuição que atende a sub-região com facilidade de acesso a fornecedores de peças, serviços diversos e matéria prima; presença de financiamento através da agência local do BASA S/A; disponibilidade de serviços técnicos existentes em razão da importância da cidade como polo regional, que recebe grande número de embarcações diariamente, demandando reparos, consertos etc. Porém, pelo crescente crescimento urbano em bairros periféricos oriundos de ocupações irregulares, forma-se a principal função da atividade: atender a demanda popular urbana do STUR, propiciando complementaridade à combalida economia urbana, intensificando a navegação sub-regional.

Tem-se observado recentemente o processo de construção e evolução do trabalho novo com uso de madeira, ferro e alumínio. O que mais impressiona no processo construtivo é a ausência de planta, projeto, desenho, croquis ou qualquer outro tipo de registro gráfico. Foram registrados alguns gabaritos (moldes de madeira), mas a oralidade e o senso prático são as principais maneiras de construir. Dimensões, curvaturas e encaixes, são feitos "a olho", como dizem os carpinteiros. O início da construção ocorre com a montagem da peça horizontal na base, chamada quilha, que geralmente é feita de madeira mais resistente como o pau d'árco ou maçaranduba. Ela dita o tamanho da embarcação e sustenta as demais peças encaixadas acima. O talha-mar, que conserva nome das antigas embarcações marítimas e étermo herdado da carpintaria portuguesa, compõe a peça frontal que, agora "talha-rios", também requer madeira mais resistente como as da quilha.

Os demais componentes da estrutura do barco são montados separadamente (alcatrate, cavernas, cambotas, escoas, falca, frisos, entre outros). O beneficiamento é realizado com equipamentos no próprio estaleiro: serra circular, tupia, serra de fita, "desengrosso", plaina e banca de lixa. Algumas máquinas são feitas pelos próprios carpinteiros. Bem mais baratas, têm menor segurança e precisão nas tarefas. Molas de caminhão ou de carros antigos e suspensões de ferro são notadas no entorno das máquinas. Servem de matéria prima para fazer lâminas e serras para desbaste da madeira. Uma verdadeira arte do improviso incentivada pela escassez de recursos e necessidade de economizar.

Entre as técnicas usadas, a que chama mais atenção é o uso do enxó (figura 4). Este instrumento é uma espécie de enxada construída artesanalmente pelos próprios carpinteiros que serve para talhar curvaturas em diversas partes das peças. Os carpinteiros relataram não existir máquina de manuseio rápido e com peso leve que faça tal trabalho. A solução era alternar o uso com outras ferramentas elétricas. Outro fator é a constante falta de energia que é comum em cidades do interior do Amazonas. O sistema de geração de eletricidade é composto por centrais termelétricas movidas a diesel (não integradas ao sistema elétrico nacional). Isso torna as ferramentas manuais ainda mais necessárias durante os "apagões". O arco de pua é outra ferramenta manual muito usada que tem o papel de furadeira ou parafusadeira. 

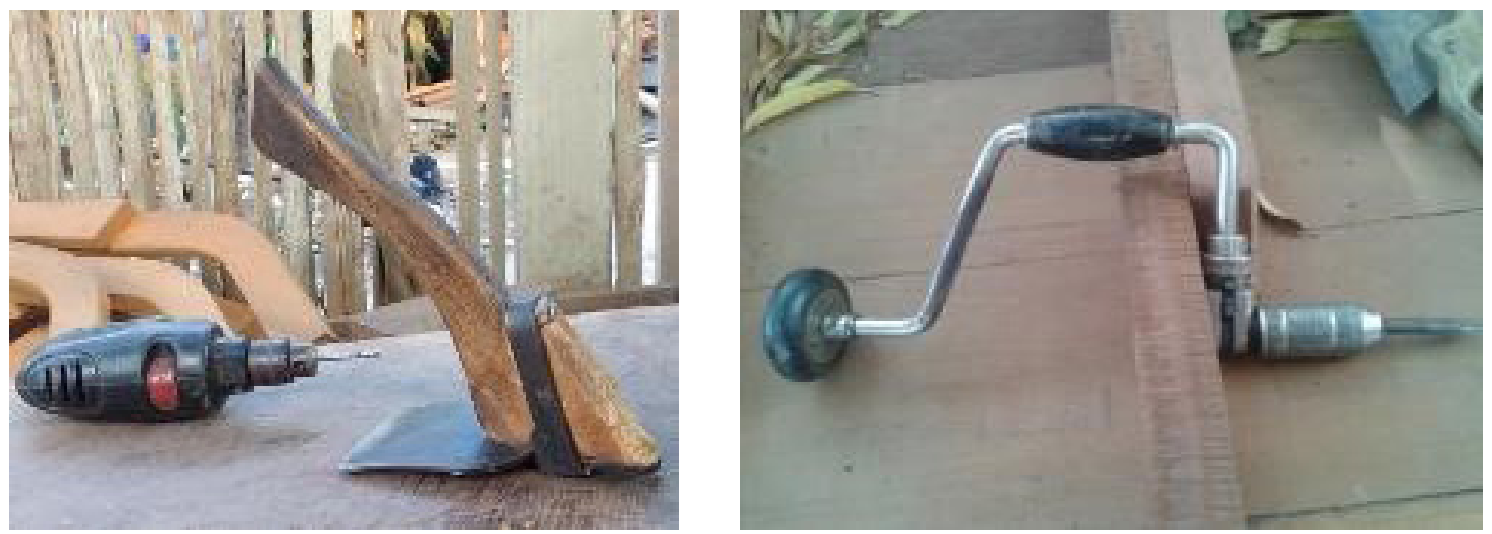

FIGURA 4 - Furadeira e "enxó" (esquerda), e arco de pua (direita). FOTO: Estevan Bartoli (06/07/2014).

Com a introdução dos motores na maioria das embarcações de pequeno porte e o aumento frota naval sub-regional e da movimentação na lagoa da Francesa, diversos postos de combustíveis flutuantes surgiram no entorno. Isso ocorreu juntamente com a construção de barcos para transporte de combustível que também exercem função de posto flutuante. Alguns estaleiros navais locais passaram a construir tais embarcações de ferro. Em trabalho de campo, conversamos com o proprietário de um posto que estava construindo, na margem de seu terreno, uma embarcação média de ferro para transporte de combustível. Questionamos sobre as técnicas, projeto e executores do trabalho. Ele descreveu que a construção contava com saberes de antigos mestres associada a soldadores experientes que haviam trabalhado em muitas alegorias dos bois-bumbás da cidade. Disse também que não havia qualquer projeto ou planta como guia.

Constatamos, nesse caso, a junção do saber tradicional às técnicas e materiais modernos, com outra utilidade da embarcação. Assim realiza-se parte da materialidade do que estamos chamando de Sistema Territorial Urbano-Ribeirinho enquanto sistema mediador multidimensional. O design da embarca- ção de ferro é igual ao das de madeira. Pelo relato do proprietário, há necessidade da embarcação ter estabilidade no rio e os antigos mestres conhecem curvaturas adequadas dos "cascos". Relatou ainda experiências frustradas de construção sem auxílio de antigos mestres, que davam o "prumo ao casco", apenas com conhecimento tácito.

Atualmente, embarcações de alumínio têm ganhado cada vez mais espaço. Muito mais leves e de fácil manuseio, também são incentivadas pelas facilidades de financiamento. Segundo entrevistas, os barcos mais vendidos entre dois e três anos atrás eram as canoas de madeira de 7 metros. Hoje, estes modelos recebem menos encomendas e são, paulatinamente, substituídos pelos botes de alumínio.

Mudanças também ocorrem no processo de calafetagem para vedação das embarcações. A prática antiga era feita com produtos da floresta, fibras e óleos extraídos de árvores. Hoje esses itens são substituídos por produtos industrializados, embora o processo ainda seja extremamente laborioso, dependente unicamente do trabalho braçal e manual. Pequenas espátulas que infiltram a fibra de algodão nas lacunas entre as tábuas de itaúba são utilizadas, com posterior vedação com massa e lixamento final. 
A nomenclatura dos tipos de embarcações varia em cada região da Amazônia. Fragatas, bargantins, batelões, canoas, bajaras, balieiros, chatinhas são alguns dos nomes encontrados na literatura sobre o tema. Variam de acordo com função, tipo de carga e necessidade de acesso.

Em determinados períodos do ano, somente embarcações pequenas e médias são capazes de adentrar em cursos d'água estreitos e rasos. A bajara é uma delas. Variando de 7 a 14 metros, trata-se de um modelo muito usado na região como uma espécie de canoa de porte maior. Tem a vantagem de acessar cursos mais rasos, se deslocando mais rapidamente. Entrevistamos um agricultor e pescador, comprador de uma bajara no estaleiro do Eraldo que relatou ser o barco ideal para chegar ao sítio que possuía, através de pequenos furos e lagos. Relatou ainda que a bajara serviria como moradia, pois constantemente acessava a cidade com seus dois filhos e esposa, não possuindo condições de comprar ou alugar uma casa na cidade. Ressaltamos o papel social que a atividade desempenha para a circulação necessária sub-regional. As embarcações passam assim a internalizar contradições urbanas como o déficit habitacional (Bartoli, 2017).

As tipologias de embarcações descritas em Bartoli (2017) variam de forma marcante quanto ao uso/função, tipo de carga e lugares acessados. São conectores e mediadores do STUR, muito presentes na paisagem de Parintins.

$\mathrm{O}$ acesso a motores e barcos através de linhas de crédito e programas governamentais incentivou a produção naval na cidade, que cresceu nos últimos anos. Assim como as movelarias, a produção nos tilheiros parece ter "parado no tempo". Poucas inovações técnicas demonstram o "fechamento" relativo do sistema quanto às trocas externas, intercâmbios e buscas de novas formas de produção desse meio de transporte.
Apesar de novos materiais utilizados, não constatamos mudança substancial no processo produtivo do chamado casco, com manutenção de precária divisão social do trabalho. Entretanto, a interação com a mediação urbana vem sendo primordial para a atividade. Os complementos necessários como ferragens, motores e acabamento final demonstraram dois tipos de dinâmica já assinalados: i) processos criativos para superar escassez técnica local, como na fundição, na fabricação das máquinas processadoras e na adaptação de motores importados a estruturas de madeira; e ii) aquecimento do mercado local de peças e serviços complementados com motores modernos oriundos de transnacionais com a Yamaha, MWM ou Honda.

A Itaúba (Mezilaurus itauba - Lauraceae) é a espécie de madeira mais utilizada na maioria dos estaleiros. É difícil de serrar, fácil de aplainar e com secagem lenta e enorme resistência à água. Cidades como Parintins cumprem papel de pressionar estoques ainda existentes por atividades diversas. A Itaúba, assim como outras madeiras averiguadas no caso das movelarias, começa a dar sinais de escassez na sub-região, passando a ser extraída nas cabeceiras de rios e matas interiores. É notório que a Amazônia urbanizada tem contribuído para a alteração de estoques diversos de biodiversidade. Em diversas atividades com uso de madeira de Parintins, prevalece a inexistência de certificados de origem, principalmente o Documento de Origem Florestal (DOF). Isso ocorre mesmo tendo na cidade o Instituto de Desenvolvimento Agropecuário e Florestal Sustentável do Amazonas (IDAM) como mediador para obtenção desse documento junto ao Instituto de Proteção Ambiental do Amazonas (IPAAM). Tais fatores impelem fragilidade ao setor e isso passa a impactar negativamente o tipo de uso do território. Confere-se nesse consumo a demanda para extração ilegal, sobrecarregando a capacidade de reposição natural das espécies. 
O preocupante quadro existente quanto à disponibilidade de madeira é fator crucial no futuro da atividade. Mesmo não constituindo um coletivo organizado com projeto comum e coesão social, trata-se de sistema territorial de alto valor contextual com técnicas disponíveis aptas a avanços e evolução. Como salientou um dos carpinteiros, seus barcos ainda servem primordialmente aos homens simples dos interiores, agricultores, pescadores ou pequenos criadores de gado.

Atendendo aos pedidos de encomendas de vários municípios circunvizinhos como Maués, Boa Vista do Ramos, Barreirinha e Nhamundá, o polo naval de Parintins se consolida como sistema territorial com possibilidade evolutiva. A aglomeração e centralidade da cidade desempenham papel importante.

A circulação de madeira para a cidade e barcos vendidos para municípios do interior e comunidades demonstra influência das ações dessa atividade na rede urbana sub-regional.

\section{Considerações finais}

Como constatações finais, elencamos as principais caraterísticas da atividade enquanto subsistema territorial que dinamiza atividades no STUR.

a) Relações histórico-culturais: Atividade tradicional de relação intensa com a cultura local, hibridizando técnicas modernas às vernaculares e possibilitando circulação de populações rurais e urbanas durantes crises de ciclos econômicos sucessivos, sendo elemento importante na retomada de novas atividades.

b) Características de sítio e situação da cidade: Ocorrem adaptações frequentes das atividades laborais às oscilações de sazonalidade. Presente em bairros antigos devido a características do sítio urbano (arquipélago fluvial), sofrem pressão pela valorização de beiras de rio por parte dos agentes do STUF. A situação da cidade enquanto polo sub-regional é favorável ao desenvolvimento da atividade que teve demanda crescente tanto pelo crescimento da população de bairros periféricos (STUR), como das atividades mercantis dominantes (STUF).

c) Relação com os recursos locais, capacidade de processamento; relações com o milieu: Espécies de madeira ainda disponíveis, mas em maior parte de origem ilegal e em estágio preocupante quanto à disponibilidade futura, colocando em risco o equilíbrio necessário para a continuidade da espécie. Desenha-se uma cadeia produtiva incompleta e insustentável devido à ausência de reposição do estoque madeireiro; é perceptível a estagnação quanto a avanços técnicos (fechamento operacional de trocas de informações); Milieu: conhecimento e tradição da atividade com concentração na cidade de conjunto de atividades que se complementam.

d) Abrangência da área de atuação e influência econômica; capacidade de ativação de áreas no território: Atende diversas comunidades, municípios vizinhos, setores dominantes da economia (comércio, madeira e gado) e setores populares da cidade, propiciando reforma ou construção de embarcações. Importante composição na economia urbana. Consome itens de casas comerciais (motores, peças, ferragens, material de acabamento), servindo de base tanto ao STUF como ao STUR.

e) Autonomia relativa frente às redes locais de poder; capacidade de criar relações em escalas variadas: Situação frágil de dependência frente às redes de poderes locais devido à baixa organização coletiva e ausência da formação de projeto ou aprendizado mútuo; relações externas ao sistema quase nulas; ausência de trocas de informação com sistemas externos, salvo migração de mestres de outras localidades. 
f) Papel da atividade na cidade para proposição de circuitos potenciais: Possui enorme potencial de evolução das relações territoriais a partir da cidade. Pela experiência de construção e adaptações, além de cumprir base para propiciar circulação sub-regional, o subsistema é propício para contemplar cadeia produtiva completa desde que haja reposição do estoque madeireiro (reflorestamento) ou manejo e certificação.

\section{Referências}

Bagliani, M.; Dansero, E. Verso uma territorialitá sostenibile: um aproccio per sistemi locali territoriali. In: Dematteis, G. et al. (Org.). Territorialità, sviluppo locale, sostenibilità: Il modello Slot. Milano: Angeli, 2005.

Bartoli, E. Ações Indígenas Sateré-Mawé na Cidade de Parintins (AM) e a Formação de Sistemas Locais Territoriais Urbano-Ribeirinhos. In: Anais Simpósio Nacional de geografia Urbana (SIMPURB), CD-room. Fortaleza: UFCE, 2015.

Bartoli, E. O Retorno ao Território a partir da cidade: Sistemas Territoriais Urbano-Ribeirinhos em Parintins (AM). Presidente Prudente-SP. Tese (Doutorado em Geografia) - UNESP, 2017.

Bartoli, E. Rede urbana de Parintins e Articulações a Partir de Sistemas Territoriais. In: ANAIS do VSICASA - Seminário Internacional em Ciências do Ambiente e Sustentabilidade na Amazônia. Campus Universitário da UFAM, Manaus, 14 a 17 de Agosto de 2018.

Becker, B. A Urbe Amazônida. Rio de Janeiro: Garamond, 2013.

Bertalanffy, L. von. Teoria Geral dos Sistemas. Petrópolis: Vozes, 2010.

Brandão, C. A. Território e Desenvolvimento: as múltiplas escalas entre o local e o global. Campinas: Editora da Unicamp, 2007.

Camagni, R. Economía Urbana. Barcelona: Antoni Bosch, 2005.
A plasticidade nas relações territoriais que setores populares possuem, "retornando a territórios" para manutenção da vida, permite maior variedade de escolhas, formando opções de estratégias de sobrevivência em des-continuidades evolutivas com o socioambiente: pressão de espécies para o sistema mercantil (valor de uso) / uso de espécies para consumo popular e manutenção da vida (valor de troca).

Cavalcante, P. B.; Frikel, P. A. Farmacopéia Tiriyó / Estudo Etno-botânico. Belém: Gráfica Falangola Editora LTDA, 1973.

Clement, C. R.; Junqueira, A. B. Plantas Domesticadas: uma história fascinante. Scientific American, Coleção Amazônia, 1998.

Dematteis, G. Progetto implícito. Il contributo della geografia umana alle science del território. Milão: Franco Angeli, 1995.

Dematteis, G. Il sistemi territoriali in um'ottica evoluzionista. In: Dematteis, G. et al. (Orgs.). Territorialità, sviluppo locale, sostenibilità: il modello Slot. Milano: Angeli, 2005.

Dematteis, G. Paesaggio come "codice genético". In: Balleti, F. (Org.). Sapere técnico, Sapere Locale. Firenze: Alinea, 2007.

Dematteis, G. Sistema Local Territorial (SLoT): um instrumento para representar, ler e transformar o teritório. In: Alves, A. et al. (orgs.). Desenvolvimento Territorial e Agroecologia, 2008.

Griffith, J. J.; Berdague, C. Autopoiese Urbana e Recuperação Ambiental. Saneamento Ambiental, 16(120), 2006.

Machado, L. O. A Urbanização e Mercado de Trabalho na Amazônia Brasileira. Cadernos do IPPUR, 1, 109-138, 1999.

Machado, L. Região, Cidades e Redes Ilegais: geografias alternativas na Amazônia Sul-Americana. In: Gonçalves, 
M. F. et al. (Orgs.). Regiões e Cidades: cidades nas regiões. São Paulo: Edunesp, 2003.

Machado, L. Sistemas e Redes Urbanas como Sistemas Complexos Evolutivos. In: Carlos, A. F. A. et al. (Orgs.). Dilemas Urbanos. São Paulo: Contexto, 2005.

Magnaghi, A. Il progetto locale. Torino: Bollati Boringhieri, 2010a.

Magnaghi, A. Montespertoli: le mappe di comunità per lo statuto del território. Firenze: Alinea, 2010b.

ONU - Organização das Nações Unidas. PNDU - Programa de las Naciones Unidas para el Desarrollo. Nova York, 1997.

Pumain, D. An Implicit Large Territorial-tecnhical System. Paris, Flux: 1995.

Raffestin, C. Por Uma Geografia do Poder. São Paulo: Ática, 1993.

Ribeiro, B. Amazônia urgente. Belo Horizonte, Itatiaia, 1990.
Santos, M.; Silveira, M. L. Brasil: território e sociedade no limiar do século XXI. Rio de Janeiro: Record, 2003.

Saquet, M. A. Abordagens e Concepções de Território. São Paulo: Expressão Popular, 2007.

Saquet, M. A. Por uma Geografia das Territorialidades e das Temporalidades: uma concepção multidimensional voltada para a cooperação e para o desenvolvimento territorial. São Paulo: Outras Expressões, 2011.

Schor, T.; Oliveira, J. A. Parintins: a geografia da saúde na formação da cidade média de responsabilidade territorial no Amazonas. In: Bartoli, E. et al. (Org.). Parintins: Sociedade, Territórios e Linguagens. Manaus: EDUA, 2016.

Sommella, R.; Viganoti, L. Território e sviluppo locale nel mezzogiorno. In: Dematties, G. et al. (Orgs.). Territorialità, Sviluppo Locale, sostenibilità: Il modello SLoT. Roma: Franco Angeli, 2005.

THECNA - Transporte Hidroviário e Construção Naval na Amazônia. Relatórios I e II. Manaus, AM. 2006/2007/2008. 2008 . 